\title{
EVIDENCE OF SPECIES-SPECIFIC NEIGHBORHOOD EFFECTS IN THE DIPTEROCARPACEAE OF A BORNEAN RAIN FOREST
}

\author{
Peter STOll ${ }^{1}$ ANd David M. Newbery \\ Institute for Plant Sciences, Vegetation Ecology Section, University of Bern, CH-3013, Bern, Switzerland
}

\begin{abstract}
Although accumulating evidence indicates that local intraspecific densitydependent effects are not as rare in species-rich communities as previously suspected, there are still very few detailed and systematic neighborhood analyses of species-rich communities. Here, we provide such an analysis with the overall goal of quantifying the relative importance of inter- and intraspecific interaction strength in a primary, lowland dipterocarp forest located at Danum, Sabah, Malaysia. Using data on 10 abundant overstory dipterocarp species from two 4-ha permanent plots, we evaluated the effects of neighbors on the absolute growth rate of focal trees (from 1986 to 1996) over increasing neighborhood radii (from 1 to $20 \mathrm{~m}$ ) with multiple regressions. Only trees $10 \mathrm{~cm}$ to $<100 \mathrm{~cm}$ girth at breast height in 1986 were considered as focal trees. Among neighborhood models with one neighbor term, models including only conspecific larger trees performed best in five out of 10 species. Negative effects of conspecific larger neighbors were most apparent in large overstory species such as those of the genus Shorea. However, neighborhood models with separate terms and radii for heterospecific and conspecific neighbors accounted for more variability in absolute growth rates than did neighborhood models with one neighbor term. The conspecific term was significant for nine out of 10 species. Moreover, in five out of 10 species, trees without conspecific neighbors had significantly higher absolute growth rates than trees with conspecific neighbors. Averaged over the 10 species, trees without conspecific neighbors grew $32.4 \mathrm{~cm}^{2}$ in basal area from 1986 to 1996, whereas trees with conspecific neighbors only grew $14.7 \mathrm{~cm}^{2}$ in basal area, although there was no difference in initial basal area between trees in the two groups. Averaged across the six species of the genus Shorea, negative effects of conspecific larger trees were significantly stronger than for heterospecific larger neighbors. Thus, high local densities within neighborhoods of $20 \mathrm{~m}$ may lead to strong intraspecific negative and, hence, density-dependent, effects even in species-rich communities with low overall densities at larger spatial scales. We conjecture that the strength of conspecific effects may be correlated with the degree of host specificity of ectomycorrhizae.
\end{abstract}

Key words: density dependence; Dipterocarpaceae; ectomycorrhizae; growth increment; host specificity; individual-based models; interspecific vs. conspecific neighborhood effects; Sabah, Borneo, Malaysia; Shorea spp.; tropical rain forest.

\section{INTRODUCTION}

The competitive exclusion principle states that, given a suite of species, interspecific competition will result in the exclusion of all but one species. This is particularly true if there is little or no temporal and spatial variation in the environment and the species are ecologically similar. Yet, the number of similar plant species coexisting in tropical forests may reach extraordinarily high levels. Explaining how hundreds of species can coexist within a single hectare in the face of potential competitive exclusion remains challenging and has generated many hypotheses. Among them, negative density dependence receives strong support as

Manuscript received 6 October 2004; revised 19 April 2005; accepted 6 May 2005. Corresponding Editor: N. C. Kenkel.

${ }^{1}$ Present address: Institute for Environmental Sciences, Section Conservation Biology, University of Basel, St. Johanns-Vorstadt 10, CH-4056 Basel, Switzerland.

E-mail: peter.stoll@unibas.ch judged in a recent review (Wright 2002). Negative density-dependent effects occur when nearby conspecifics decrease individual performance (i.e., recruitment, survival, or growth). For example, recruitment for abundant species (Hubbell et al. 1990, Condit et al. 1992), and more generally at the community level (Wills et al. 1997, Wills and Condit 1999, Harms et al. 2000), has been shown to be negatively density dependent. Similarly, long-term survival (Hubbell et al. 2001) and mortality (Peters 2003) have been shown to be negatively density dependent for some species. Finally, growth of seedlings ( $<8 \mathrm{~cm}$ girth at breast height) and saplings $(<4 \mathrm{~cm}$ diameter) has also been shown to be negatively density dependent (Connell et al. 1984, Uriarte et al. 2004b). There is, however, comparatively little empirical evidence of density-dependent effects on the growth of medium-sized trees and the question arises whether or not such density-dependent effects on growth exist and may contribute to the maintenance of tree species diversity. Moreover, if such species- 
specific effects exist and can be detected, they will challenge neutral theories on biodiversity (e.g., Hubbell 2001), which assume that hetero- and conspecific neighbors have equivalent, or at least similar, effects on individual performance.

Interactions among plants and other sessile organisms are local processes that usually extend over limited distances. Therefore, the spatial pattern of individuals within and among species is central in ecological theory (Huston et al. 1988, Pacala 1997, Dieckmann et al. 2000) because the frequency with which individuals have other individuals of the same or different species as neighbors depends less on the relative abundance than on the particular spatial pattern. However, pattern analyses of fully mapped tree census plots at six different sites in tropical forests, including dry deciduous to wet evergreen forests on two continents, showed that nearly every species was more aggregated than a random distribution (Condit et al. 2000). Intraspecific encounters, therefore, may be much more frequent than interspecific encounters because of aggregated spatial patterns. Although overall densities of most species in very diverse communities are necessarily low (Whitmore 1984, Huston 1994, Richards 1996), local densities can nevertheless reach very high levels. These local densities are most relevant for performance of individual plants (Harper 1977). This implies that analysis and models to address ecological questions such as density dependence need to focus on individuals and adopt a spatially explicit neighborhood approach.

The neighborhood view of plant interactions has received much attention in population ecology of single species (Stoll and Weiner 2000). However, in very species-rich communities such as tropical forests, we cannot yet generalize about the spatial scales over which neighbors influence different plant population processes (Hubbell et al. 1990). Several factors may explain why. For example, different approaches and competition indices have been applied (Liu and Ashton 1995, Gourlet-Fleury 1998, Moravie et al. 1999, Uriarte et al. 2004b) to only a few sets of long-term observational and experimental data (Gourlet-Fleury and Houllier 2000). Similarly, neighborhood approaches require the complete mapping of all individuals in addition to basic demographic measurements such as recruitment, growth, and mortality. Forest stand models usually include submodels for recruitment, growth, and mortality, but the level of detail may vary considerably among them (see Pacala et al. 1993, Pacala et al. 1996, Keane et al. 2001).

Liu and Ashton (1998) used a hierarchically structured, spatially explicit, and individual-based stochastic approach to model regeneration, growth, death, spatial interactions, and environmental factors. Although they concluded that model simulation results agreed well with independent field census data in terms of species richness, species composition, tree abundance, and basal area at two spatial scales, some of their basic assumptions remain unjustified. In particular, their growth submodel uses total basal area of all trees within a grid cell of $10 \times 10 \mathrm{~m}$ to quantify neighbor effects on relative growth of individual trees within the cells. However, size of the neighborhood may vary among species, and effects of conspecific or heterospecific neighbors may vary even within species belonging to a particular guild or plant functional type. In contrast to the Liu and Ashton (1998) study, which focused on large spatial scales and relatively long-term processes for all species, Moravie et al. (1999) considered a small-scale and short-term process, i.e., diameter increment over five years, in a single species (Vateria indica, a light-demanding dipterocarp of the upper canopy). They reported that the social status (relative position in the canopy profile) of focal trees was important, that most indices were highly correlated with one another, and that interaction distances ranged from 10 to $15 \mathrm{~m}$. One of the simplest indices, the sum of neighbors' diameters at breast height, yielded the most efficient statistical model for diameter increments of $V$. indica. Again, generalization to other species remains to be demonstrated.

Another individual diameter growth model relating annual diameter increment to variables describing tree size and instantaneous competition, as well as recent past evolution of competition, was developed by Gourlet-Fleury and Houllier (2000). The growth component of the single-tree, distance-dependent model took the number of neighbors located $\leq 30 \mathrm{~m}$ from the focal tree into consideration. Social status was accounted for by including neighbors with diameters at breast height (dbh) greater than or equal to the dbh of the subject tree. They concluded that competition indices needed to be asymmetric (one-sided), particularly for shadeintolerant species. In their discussion, Gourlet-Fleury and Houllier (2000) argued that the neighborhood radius should be flexible and not fixed at $30 \mathrm{~m}$.

Survival and mortality have been modeled with neighborhood approaches in Neotropical forests (Hubbell et al. 2001) and the results have been compared with those in Paleotropic forests (Peters 2003). Both studies found strong density-dependent effects, i.e., survival of focal trees at the centers of circular neighborhoods generally decreased with the density of conspecific neighbors. Although Peters (2003) used 5-, 10-, 15-, and 20-m neighborhood radii, Hubbell et al. (2001) considered those individuals to be neighbors that lay within some fixed distance (up to $30 \mathrm{~m}$ in concentric annuli of width $2.5 \mathrm{~m}$ ) of the focal individuals. However, both studies did not explicitly ask at which distance negative effects of conspecifics on focal trees survival were strongest and did not include growth in their analysis. More recently, Uriarte et al. (2004b) found differences between conspecific and heterospecific neighborhood effects on sapling growth for only six of 60 species tested at Barro Colorado Island, 


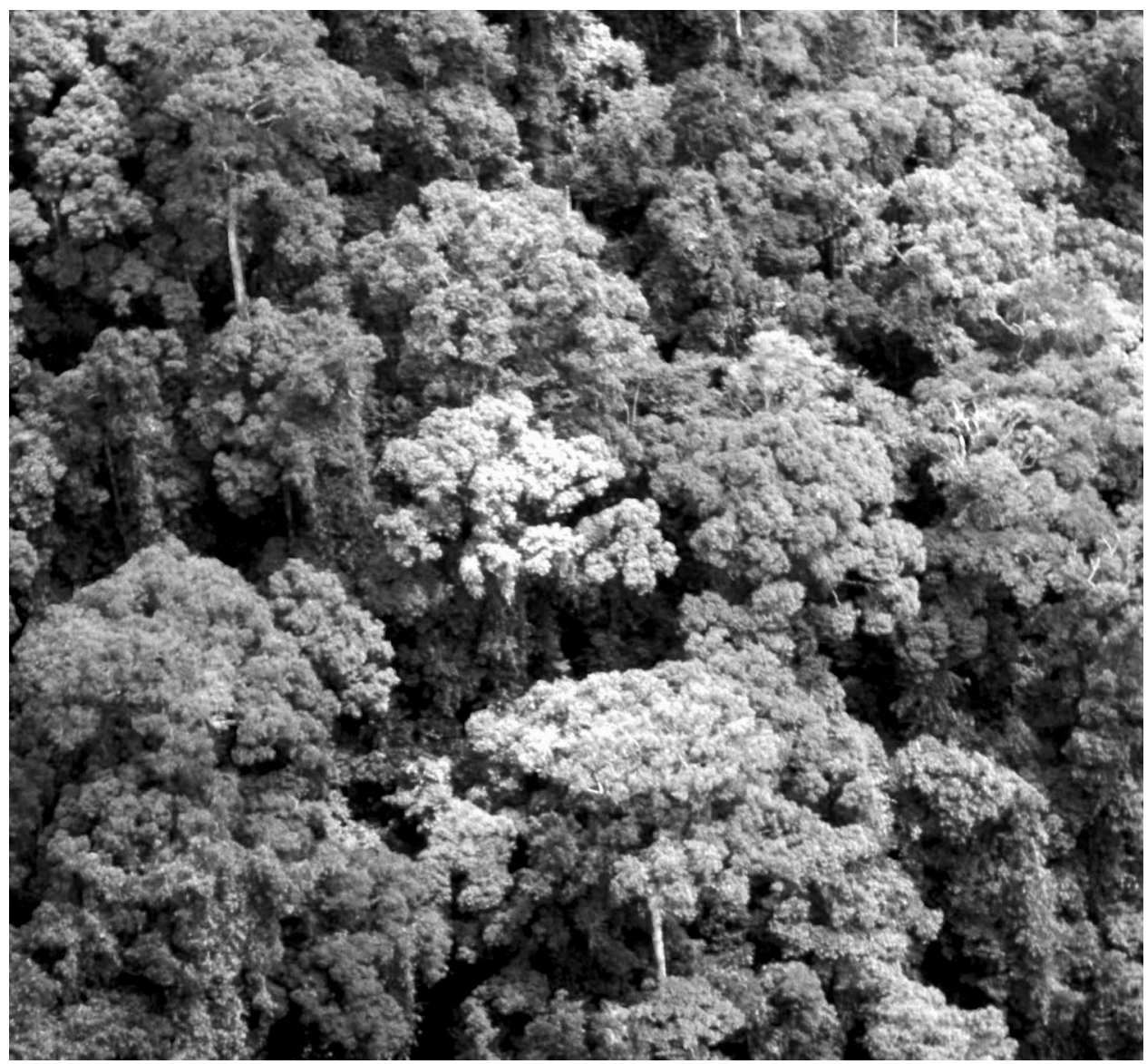

Plate 1. Lowland dipterocarp rain forest in the area of the study plots, Danum Valley Conservation Area, Sabah. Photo credit: D. Newbery.

Panama. In most cases, increased crowding around a sapling generally suppressed its growth, largely irrespective of the identity of the neighbors. Finally, Phillips et al. (2003) modeled mortality and recruitment with various approaches, and tree growth with fixed neighborhood radii of 5 and $30 \mathrm{~m}$. Their diameter increment model used a shade index, a distance-dependent competition index that took relative size differences between neighbor and focal trees into account, but no differentiation was made between heterospecific and conspecific neighbors. This last assumption needs to be explored further.

Models must make some simplifying assumptions such as applying fixed neighborhood radii or lumping species and neighbors into functional types (e.g., Köhler et al. 2000, Phillips et al. 2002). However, empirical tests of these assumptions are rare. In this paper, we focus on testing direct empirical evidence of interactions among conspecific and heterospecific neighbors at various distances on individual tree growth in a species-rich lowland dipterocarp forest.

The main overstory of lowland dipterocarp rain forest, which is the most important and extensive vegetation type of Borneo, is formed by trees of the Dip- terocarpaceae (Ashton 1982, Whitmore 1984; see Plate 1). Many species of this family are of the genus Shorea, and also belong to the most important timber trees in Southeast Asia (Ashton 1982) and especially in Sabah, Borneo (Meijer and Wood 1964, Newman et al. 1996, 1998). Many dipterocarp species (Condit et al. 2000), particularly species in the genus Shorea, show striking spatial aggregation (Ashton 1988, Okuda et al. 1997), which is usually explained by limited seed dispersal or the fact that all dipterocarp species examined so far have been found to be ectomycorrhizal (Malloch et al. 1980, Alexander and Högberg 1986, Ducousso et al. 2004). Small-scale habitat specificity may be less important than limited seed dispersal as an explanation for spatial aggregation (Newbery et al. 1996, Plotkin et al. 2000, Webb and Peart 2000). However, habitat preferences may very well explain the distribution of some species (Newbery and Proctor 1984, Newbery et al. 1986, Harms et al. 2001, Potts et al. 2002) and therefore may interact with density-dependent effects (Palmiotto et al. 2004) in creating spatial patterns.

Using a completely mapped data set from a lowland dipterocarp forest and a detailed, systematic, individual-based, and spatially explicit neighborhood ap- 
proach, we addressed four main questions. (1) Is there evidence for interference? If yes, (2) what is the relative importance of intra- and interspecific interference? (3) What are the distances over which neighborhood interactions can be detected? (4) Can neighbor effects be interpreted with specific spatial patterns (e.g., degree of clumping)?

To address the first question, we regressed absolute growth rate (AGR) from 1986 to 1996 in basal area on basal area (BA) in 1986, and asked whether trees in the neighborhood accounted for additional variation in absolute growth. Size is only one determinant of plant growth (Stoll et al. 1994, Duncan 1995); especially in dense and closed vegetation, there is usually intense interference among neighboring trees. Therefore, some of the individual variation around the size model may be explained by the presence or absence of neighboring trees. The neighborhood was evaluated over several neighborhood radii (from 1 to $20 \mathrm{~m}$ in steps of $1 \mathrm{~m}$ ) to see whether there was an optimal neighborhood radius or whether different categories of neighbors influenced the growth of focal trees at different distances. The second question was addressed by asking which category of neighbors, if any, yielded the best-fitting model. We used the following categories: all neighbors regardless of species; only heterospecifics; and only conspecifics. Each of these categories was tested using all trees (regardless of size) in the corresponding category or only trees larger than focal trees at the centers of circular and flexible neighborhoods of 1-20 m radius. The reason for contrasting all vs. only larger neighbors was to test for asymmetric competition. Because competition for light is often asymmetric, i.e., larger neighbors may have an overproportional effect compared to smaller ones (Thomas and Weiner 1989, Schwinning and Weiner 1998, Brown et al. 1999), the question was whether or not conspecific or heterospecific larger trees, compared to all neighbors in the corresponding category, explained as much or even more variation around the size model. The fourth question was tested by calculating a standard spatial pattern analysis (Ripley 1977) in order to quantify the spatial distribution of individuals as random, regular, or clumped.

\section{Material And Methods}

\section{Study site}

Two 4-ha permanent plots, each $100 \mathrm{~m}$ wide (W-E) and $400 \mathrm{~m}$ long $(\mathrm{S}-\mathrm{N})$, were set up in a lowland dipterocarp forest at Danum Valley Conservation Area,

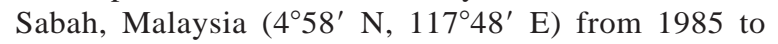
1987 (Newbery et al. 1992). All living trees $\geq 10 \mathrm{~cm}$ girth at breast height (gbh at $1.3 \mathrm{~m}$ ) were tagged, identified, mapped to the nearest $0.1 \mathrm{~m}$, and measured. The $\sim 18000$ trees in the 8 ha were completely re-enumerated in 1995-1996 (Newbery et al. 1999). For simplicity, the two sampling periods subsequently will be
TABLE 1. Basal area (BA; in 1986), rank, and contribution to total basal area of trees ( $\geq 10 \mathrm{~cm}$ girth at breast height) of all 12 overstory dipterocarp species out of the 40 most abundant species in two 4-ha plots of a Bornean rain forest.

\begin{tabular}{lcccc}
\hline \hline \multicolumn{1}{c}{ Species } & \multicolumn{3}{c}{$\begin{array}{c}\text { Contribu- } \\
\text { tion } \\
\text { to total }\end{array}$} & $\begin{array}{c}\text { Density } \\
\text { (no. } \\
\text { stems/ha) }\end{array}$ \\
\hline Shorea johorensis & 3.17 & 1 & 10.3 & 24.6 \\
Shorea argentifolia & 2.40 & 2 & 7.8 & 9.9 \\
Shorea parvifolia & 2.32 & 3 & 7.5 & 25.6 \\
Shorea pauciflora & 1.17 & 4 & 3.8 & 10.9 \\
Shorea pilosa & 0.98 & 5 & 3.2 & 14.5 \\
Shorea fallax & 0.94 & 8 & 3.1 & 45.8 \\
Parashorea malaanonan & 0.71 & 9 & 2.3 & 18.6 \\
Shorea leprosula & 0.35 & 14 & 1.1 & 7.5 \\
Vatica dulitensis & 0.29 & 22 & $<1.0$ & 8.1 \\
Dipterocarpus kerrii & 0.24 & 29 & $<1.0$ & 8.1 \\
Hopea nervosa & 0.17 & 34 & $<1.0$ & 12.4 \\
Anisoptera costata & 0.12 & 39 & $<1.0$ & 1.3 \\
\hline
\end{tabular}

Note: Only the 10 species with densities of more than eight individuals were included in subsequent neighborhood analyses.

referred to as 1986 and 1996, respectively. Details of the study site, enumeration, and tree identification can be found in (Newbery et al. 1992, 1999). The floristic composition in relation to topography, as well as gradients and patterns in the understory, are presented in Newbery et al. (1996); a description of the ecoclimatology in a broader context is given by Walsh and Newbery (1999).

\section{Species selection}

For the present analysis, we selected all 12 overstory dipterocarp species (Table 1) out of the 40 most abundant species in terms of basal area (cf. Newbery et al. 1996: Table 1). Analyses on the other mainly understory species will be presented elsewhere. Two dipterocarp species with densities $<8$ trees/ha (Shorea leprosula Miq. and Anisoptera costata Korth.) were also excluded from the analysis. Six of the remaining 10 species were in the genus Shorea (S. argentifolia Sym., S. fallax Meijer, S. johorensis Foxw., S. parvifolia Dyer, $S$. pauciflora King, and S. pilosa Ashton), and all of them ranked within the 10 most abundant species in terms of mean basal area (Table 1). The other species, were Dipterocarpus kerrii King, Hopea nervosa King, Parashorea malaanonan (Blanco) Merr., and Vatica dulitensis Sym.

\section{Evaluating the neighborhood}

Circular areas with radii up to $20 \mathrm{~m}$ around each individual tree were searched for neighbors in steps of $1 \mathrm{~m}$. A $20-\mathrm{m}$ border along each side of the two plots was imposed so that the neighborhoods of all focal trees were completely evaluated. Within these neighborhoods of increasing radius, two competition indices (number of neighbors and sum of basal area) were calculated. However, the sum of basal area was better 
TABLe 2. Overview of the different regression models and neighbor terms used to model absolute growth rate in basal area (AGR) from 1986 to 1996.

\begin{tabular}{|c|c|c|c|c|}
\hline \multirow[b]{2}{*}{$\begin{array}{l}\text { Model } \\
\text { label }\end{array}$} & \multirow[b]{2}{*}{$\begin{array}{l}\text { Dependent } \\
\text { variable, } \\
\text { absolute growth }\end{array}$} & \multicolumn{3}{|c|}{ Independent variables } \\
\hline & & $=$ Size term & $\begin{array}{l}+ \text { one } \\
\text { neighbor } \\
\text { term }\end{array}$ & $\begin{array}{l}+ \text { second } \\
\text { neighbor } \\
\text { term }\end{array}$ \\
\hline A & $\log _{10}(\mathrm{AGR})$ & $\log _{10}(\mathrm{BA})$ & & \\
\hline $\mathrm{B}_{1}$ & & & all & \\
\hline $\mathrm{B}_{2}$ & & & ALL & \\
\hline $\mathrm{B}_{3}$ & & & het & \\
\hline $\mathrm{B}_{4}$ & & & HET & \\
\hline $\mathrm{B}_{5}$ & & & con & \\
\hline $\mathrm{B}_{6}$ & & & $\mathrm{CON}$ & \\
\hline $\mathrm{C}_{1}$ & & & het & con \\
\hline $\mathrm{C}_{2}$ & & & HET & $\mathrm{CON}$ \\
\hline $\mathrm{C}_{3}^{2}$ & & & het & $\mathrm{CON}$ \\
\hline $\mathrm{C}_{4}$ & & & HET & con \\
\hline
\end{tabular}

Notes: The model label is used to refer to a particular regression model. Model A included only size; models $\mathrm{B}_{1}-\mathrm{B}_{6}$ included size plus one neighbor term; and models $\mathrm{C}_{1}-\mathrm{C}_{4}$ included size plus two neighbor terms. Capital letters in neighbor terms are used to refer to neighbor terms that only included larger neighbors relative to the focal tree in the center of the circle. The neighbor terms were calculated as the sum of basal area (BA) in 1986 (calculated from girth at breast height in 1986 and $\log _{10}$-transformed) of neighbors in different categories and evaluated in 1-m steps within circular neighborhoods from 1 to $20 \mathrm{~m}$. Independent variables to the right of the " =" sign in the column head, were used as additive ("+") terms in multiple regressions. Abbreviations: all, neighbor terms included all neighbors independent of species; het, neighbor terms included only heterospecific neighbors; con, neighbor terms included only conspecific neighbors.

correlated than the number of neighbors with the residuals from relationships of absolute growth rate and size. That is, number of neighbors did not account for as much variability as the sum of basal area. Therefore, number was not considered further. The sum of basal area of neighbors within a given radius was evaluated for six different categories of neighbors. Data from the two 4-ha plots were combined, not only to have sufficient sample sizes, but also because five species ( $D$. kerrii, H. nervosa, S. pauciflora, S. pilosa, and V. dulitensis) occurred in only one or other of the plots.

\section{Regression models}

Absolute growth rate in basal area from 1986 to 1996 (AGR in square centimeters) was modeled with various regressions of increasing complexity (Table 2). First, AGR was modeled as a function of basal area (BA) in 1986 , i.e., size at the beginning of the growth interval (model A). Second, one neighbor term was added to the size term. The neighbor term took into account all neighbors regardless of species and relative size differences (model $\mathrm{B}_{1}$ ); only heterospecific neighbors $\left(B_{3}\right)$; or only conspecific neighbors $\left(B_{5}\right)$ (both $B_{3}$ and $\mathrm{B}_{5}$ regardless of relative size differences). Each of these terms was also tested using only trees that were larger than the focal trees (corresponding models $\mathrm{B}_{2}, \mathrm{~B}_{4}$, and $\mathrm{B}_{6}$ ). Finally, to compare effect sizes of heterospecifics and conspecifics more directly, and because the corresponding terms could be correlated, the single-neighbor-term models were extended to models of size and two neighbor terms $\left(\mathrm{C}_{1}-\mathrm{C}_{4}\right)$, i.e., one for heterospecific and the other for conspecific neighbors. Two-term mod- els allowed the radii that maximize the fit to be different for conspecific and heterospecific neighbors. Note that results of models $\mathrm{C}_{3}$ and $\mathrm{C}_{4}$ were generally very similar to those of $\mathrm{C}_{1}$ or $\mathrm{C}_{2}$. Therefore, they are not presented in the Results section or in the figures, but are included in the electronic appendices. Finally, to meet the assumptions of least squares linear regression, AGR, BA, and the neighbor terms ( $\Sigma \mathrm{BA}_{1986}$ of neighbors) were $\log _{10}$-transformed. Only trees $<100 \mathrm{~cm}$ girth were used as focal trees because including the largest trees as focals resulted in skewed residuals.

The different regression models were then fitted for each species and all neighborhood radii. The regression statistics were stored such that the radius yielding the highest $R^{2}$ value (adjusted for the number of parameters, i.e., 1 - residual mean squares/total mean squares) could be found for each neighborhood model with one neighbor term. Similarly, for the neighborhood models including two neighbor terms $\left(\mathrm{C}_{1}-\mathrm{C}_{4}\right)$, the combination of heterospecific and conspecific radii yielding the highest (adjusted) $R^{2}$ values were found. The adjusted $R^{2}$ values or Akaike's information criterion (Sakamoto et al. 1986) were used because both take the number of parameters into account; this is important if models with different numbers of parameters are compared (cf. Hilborn and Mangel 1997). Because the criteria selected identical models, with very few exceptions, we report only the more familiar adjusted $R^{2}$ values as a function of neighborhood radius.

In addition to assessing significance, we also investigated the magnitude of effects by calculating variance components and effect sizes (Cohen 1977). Effect sizes 
(squared multiple partial correlation coefficients, $t^{2} /\left(t^{2}\right.$ + residual $\mathrm{df}$ ), with $t$ values from the terms of the regressions) measure the proportion of the total variance explained by each independent variable (removing the effects of all other independent variables).

Supplementary tables with all estimates, standard errors, adjusted $R^{2}$ values, best-fitting radii, $t$, and $P$ values are presented in Appendix A.

\section{Model predictions and bootstrap}

To compare the predictive accuracy of the various models, the following randomization procedure was applied. For each species, we randomly divided the available focal trees into two halves. One half was used to estimate the parameters of the statistical model and the other half was used to test the predictions made by the statistical model. This resampling was repeated 20 times. The neighborhood information on conspecific neighbors was used to divide focal trees into one group with and one group without conspecific neighbors. The neighborhood radius dividing the trees into the two groups was taken as the first maximum adjusted $R^{2}$ of model $\mathrm{B}_{5}$ ("con," all trees) with a minimum of $5 \mathrm{~m}$ in order to have sufficient individuals in the group with conspecific neighbors. This grouping allowed not only a comparison of the predictions of competing models, but also a comparison between the performances of groups of trees with and without conspecific neighbors.

\section{Pattern analysis}

The results from standard pattern analysis, i.e., a combined count-distance analysis (Ripley 1977, Haase 1995), together with a short explanation of their interpretation, may be found in Appendix B.

\section{RESULTS}

\section{Regression models}

The profiles of the adjusted $R^{2}$ values showed considerable variation among the species, models, and radii (Fig. 1).

Shorea johorensis. - The neighbor term of model $\mathrm{B}_{1}$ (i.e., including all neighbors, irrespective of species and relative size differences) was significant $(P<0.05)$ from 6 to $17 \mathrm{~m}$, and that of $\mathrm{B}_{2}$ (i.e., all neighbors, irrespective of species but larger than focal trees) was significant at neighborhood radii from 4 to $17 \mathrm{~m}$. The maximum adjusted $R^{2}$ of model $\mathrm{B}_{1}$ was $43 \%$ at $11 \mathrm{~m}$; that of $\mathrm{B}_{2}$ was $38 \%$ at $12 \mathrm{~m}$. Model $\mathrm{B}_{3}$ (heterospecific neighbors) had significant $(P<0.05)$ neighbor terms from 11 to $15 \mathrm{~m}$ and maximum adjusted $R^{2}$ of $31 \%$ at $11 \mathrm{~m}$. Model $\mathrm{B}_{4}$ (heterospecific larger neighbors) had significant neighbor terms at $6 \mathrm{~m}$ and from 11 to $17 \mathrm{~m}$ and a maximum adjusted $R^{2}$ of $29 \%$ at $12 \mathrm{~m}$. Models $\mathrm{B}_{5}$ (conspecific neighbors) and $\mathrm{B}_{6}$ (conspecific larger neighbors) were significant at neighborhood radii from 4 to $14 \mathrm{~m}$ and 3 to $16 \mathrm{~m}$, respectively. Model $B_{5}$ had a maximum adjusted $R^{2}$ of $38 \%$ at $6 \mathrm{~m} ; \mathrm{B}_{6}$ had one of
$43 \%$ at $5 \mathrm{~m}$. Models $\mathrm{C}_{1}$ and $\mathrm{C}_{2}$ (i.e., two-neighbor terms with different radii for heterospecific and conspecific $\left(\mathrm{C}_{1}\right)$ or heterospecific larger and conspecific larger $\left(\mathrm{C}_{2}\right)$ neighbors) had maximum adjusted $R^{2}$ of $57 \%$ and $56 \%$, respectively, at heterospecific radii of $11 \mathrm{~m}$ and conspecific radii of $9 \mathrm{~m}$ for $\mathrm{C}_{1}$ and heterospecific radii of $15 \mathrm{~m}$ and conspecific radii of $6 \mathrm{~m}$ for $\mathrm{C}_{2}$.

Shorea argentifolia.-Models $\mathrm{B}_{1}-\mathrm{B}_{4}$ were never significant. By contrast, model $\mathrm{B}_{5}$ was significant from 17 to $20 \mathrm{~m}$ and model $\mathrm{B}_{6}$ was significant at 19 and $20 \mathrm{~m}$ with an $R^{2}>60 \%$. Models $\mathrm{C}_{1}$ and $\mathrm{C}_{2}$ had highest $R^{2}$ values at conspecific radii of $19 \mathrm{~m}$ and heterospecific radii of $18 \mathrm{~m}$.

Shorea parvifolia.-Models $\mathrm{B}_{1}$ and $\mathrm{B}_{2}$ had highest $R^{2}$ values at 5 and $4 \mathrm{~m}$. Model $\mathrm{B}_{3}$ was never significant and $\mathrm{B}_{4}$ was only significant at $1 \mathrm{~m}$. Model $\mathrm{B}_{5}$ was significant at 4,16 , and $17 \mathrm{~m}$, and model $\mathrm{B}_{6}$ showed additional significances from 8 to $15 \mathrm{~m}$. The two-neighbor-term model $\mathrm{C}_{2}$ had considerably higher $R^{2}$ values and a maximum of almost $50 \%$ at heterospecific radii of $1 \mathrm{~m}$ and conspecific radii of $14 \mathrm{~m}$.

Shorea pauciflora.-Model $\mathrm{B}_{1}$ was significant from 7 to $15 \mathrm{~m}$ and $\mathrm{B}_{2}$ at $4 \mathrm{~m}$ and from 8 to $15 \mathrm{~m}$. Moreover, model $\mathrm{B}_{2}$ always had higher $R^{2}$ values than model $\mathrm{B}_{1}$. Maximum adjusted $R^{2}$ values were $\sim 40 \%$ and $44 \%$ at $9 \mathrm{~m}$. Models $\mathrm{B}_{3}$ and $\mathrm{B}_{4}$ showed a similar pattern with a maximum of $41 \%$ at $9 \mathrm{~m}$ for $\mathrm{B}_{4}$. Model $\mathrm{B}_{5}$ was not significant at any of the neighborhood radii. In contrast, model $\mathrm{B}_{6}$ was significant at 7 and $10 \mathrm{~m}$ but the $R^{2}$ values were well below those of any of the other models with a single neighborhood term. The models with two neighbor terms reached $R^{2}$ values of $44 \%$ and $53 \%$ at heterospecific and conspecific radii of $10 \mathrm{~m}$.

Shorea pilosa.-Models $\mathrm{B}_{1}$ and $\mathrm{B}_{2}$ were significant at $6 \mathrm{~m}$ and both peaked in terms of adjusted $R^{2}$ at $6 \mathrm{~m}$. Models $\mathrm{B}_{3}$ and $\mathrm{B}_{4}$ were not significant at any of the neighborhood radii. Models $\mathrm{B}_{5}$ and $\mathrm{B}_{6}$ again showed a similar pattern with the highest $R^{2}$ value of $38 \%$ for model $\mathrm{B}_{5}$ at $5 \mathrm{~m}$. Model $\mathrm{C}_{1}$ had maximal $R^{2}$ values higher than any of the models with one neighbor term only. The maximum $R^{2}$ value for model $\mathrm{C}_{1}(45 \%)$ was at a heterospecific radius of $6 \mathrm{~m}$ and conspecific radius of $5 \mathrm{~m}$.

Shorea fallax.-Model $\mathrm{B}_{1}$ was significant at neighborhood radii of 3 and $4 \mathrm{~m}$ and peaked at $3 \mathrm{~m}$. Model $\mathrm{B}_{2}$ was only significant at $3 \mathrm{~m}$. Model $\mathrm{B}_{3}$ was only significant at a neighborhood radii of $3 \mathrm{~m}$, whereas model $B_{4}$ was never significant. In contrast, models $B_{5}$ and $\mathrm{B}_{6}$ again were very similar and significant over almost all of the neighborhood radii. Both reached maximum $R^{2}$ values over $45 \%$ and peaked at 4 and 6 $\mathrm{m}$, respectively. Models $\mathrm{C}_{1}$ and $\mathrm{C}_{2}$ reached $R^{2}$ values around $50 \%$. The peak for $\mathrm{C}_{1}$ was at a heterospecific radius of $3 \mathrm{~m}$ and conspecific radius of $4 \mathrm{~m}$. On the other hand, model $\mathrm{C}_{2}$ peaked at a heterospecific radius of $3 \mathrm{~m}$ and conspecific radius of $6 \mathrm{~m}$.

Among the other four dipterocarp species, Parashorea malaanonan showed little, and Dipterocarpus 


\section{S. johorensis}
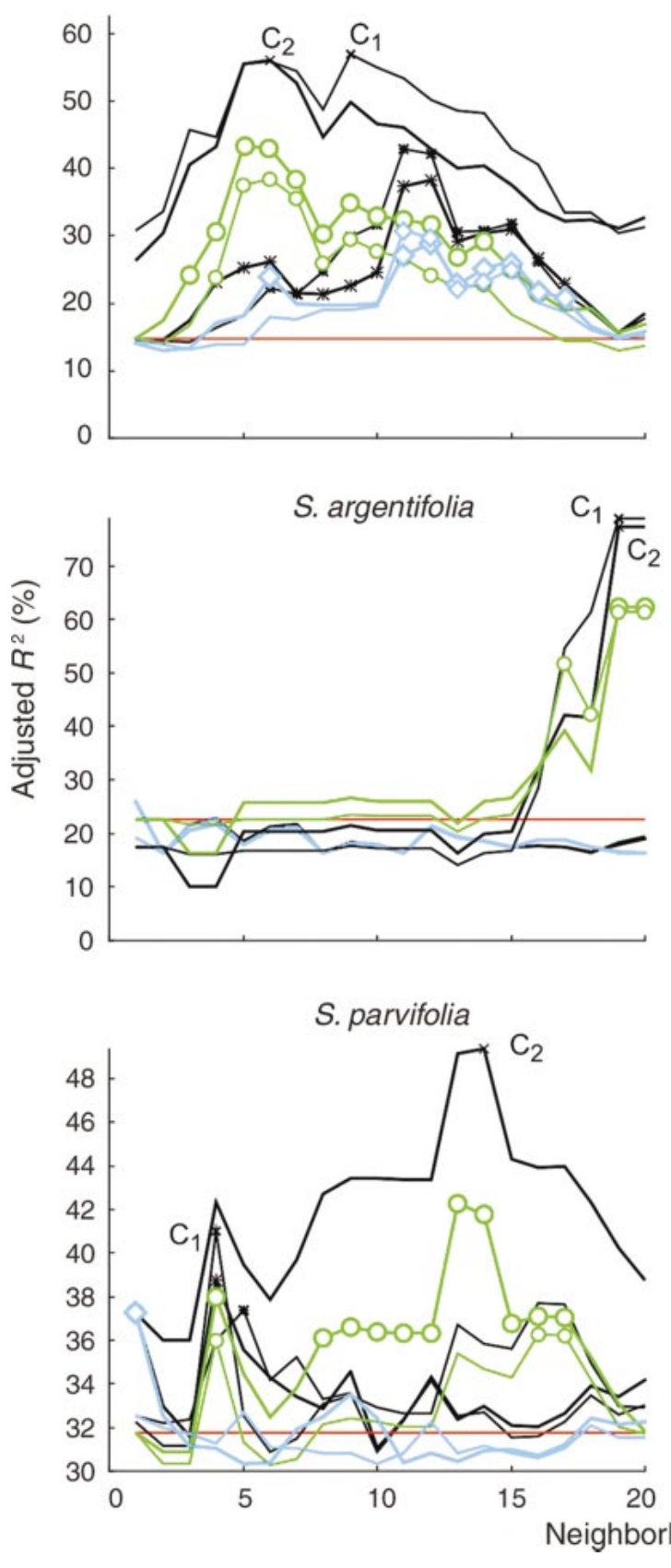
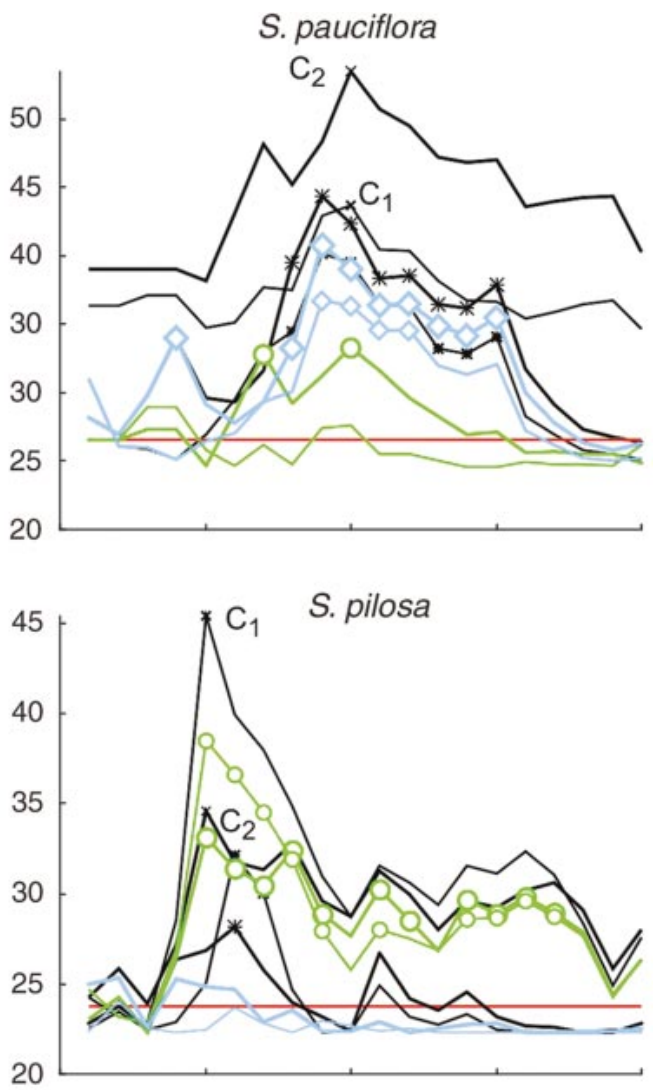

S. fallax

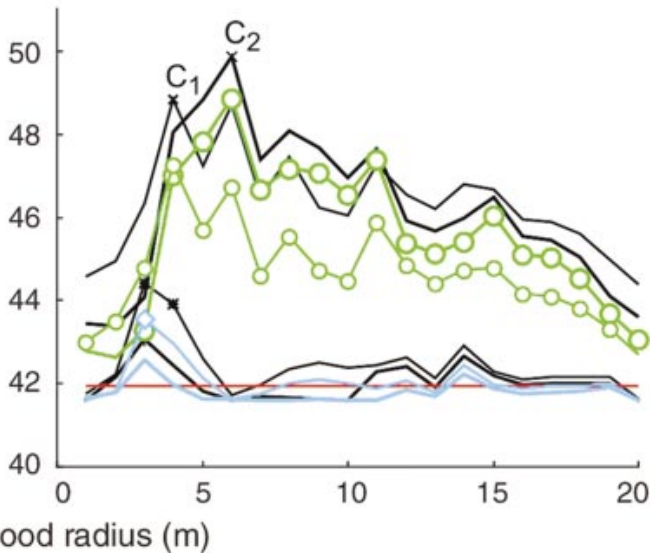

FIG. 1. Variance accounted for (adjusted $R^{2}$ ) in size and neighborhood models over neighborhood radii (m) of six Shorea species and four other dipterocarp overstory species at Danum (Sabah, Malaysia). Absolute growth rate (AGR) in basal area (1986-1996) was modeled as function of size, i.e., basal area (BA) in 1986, and size plus one or two neighbor terms ( $\sum$ BA of neighbors in 1986). All terms were $\log _{10}$-transformed. The adjusted $R^{2}$ of the size-alone model (A) is independent of the neighborhood radius and is represented by the horizontal red line. Neighborhood models with one neighbor term are represented by thin lines and small symbols if relative size differences of the corresponding neighbor category and focal trees were ignored (models $\mathrm{B}_{1}, \mathrm{~B}_{3}$, and $\mathrm{B}_{5}$ ). Thick lines and large symbols are used for neighborhood models with one neighbor term that only considered neighbors larger than the focal trees (models $\mathrm{B}_{2}, \mathrm{~B}_{4}, \mathrm{~B}_{6}$ ). If the corresponding neighbor terms were significant $(P<0.05)$, symbols were used as follows: stars $(*, *)$ for neighborhood models including all neighbors (models $\mathrm{B}_{1}, \mathrm{~B}_{2}$, black lines), diamonds $(\diamond, \diamond)$ for neighborhood models including only heterospecific neighbors (models $\mathrm{B}_{3}, \mathrm{~B}_{4}$, blue lines), and circles $(\mathrm{O}, \mathrm{O})$ for neighborhood models including only conspecific neighbors (models $\mathrm{B}_{5}, \mathrm{~B}_{6}$, green lines). Adjusted $R^{2}$ values of the neighborhood models with two neighbor terms $\left(\mathrm{C}_{1}\right.$ and $\left.\mathrm{C}_{2}\right)$ are presented. Note the different axis scaling for different species; in particular, the $y$-axis starts at zero only for $S$. johorensis and S. argentifolia. 


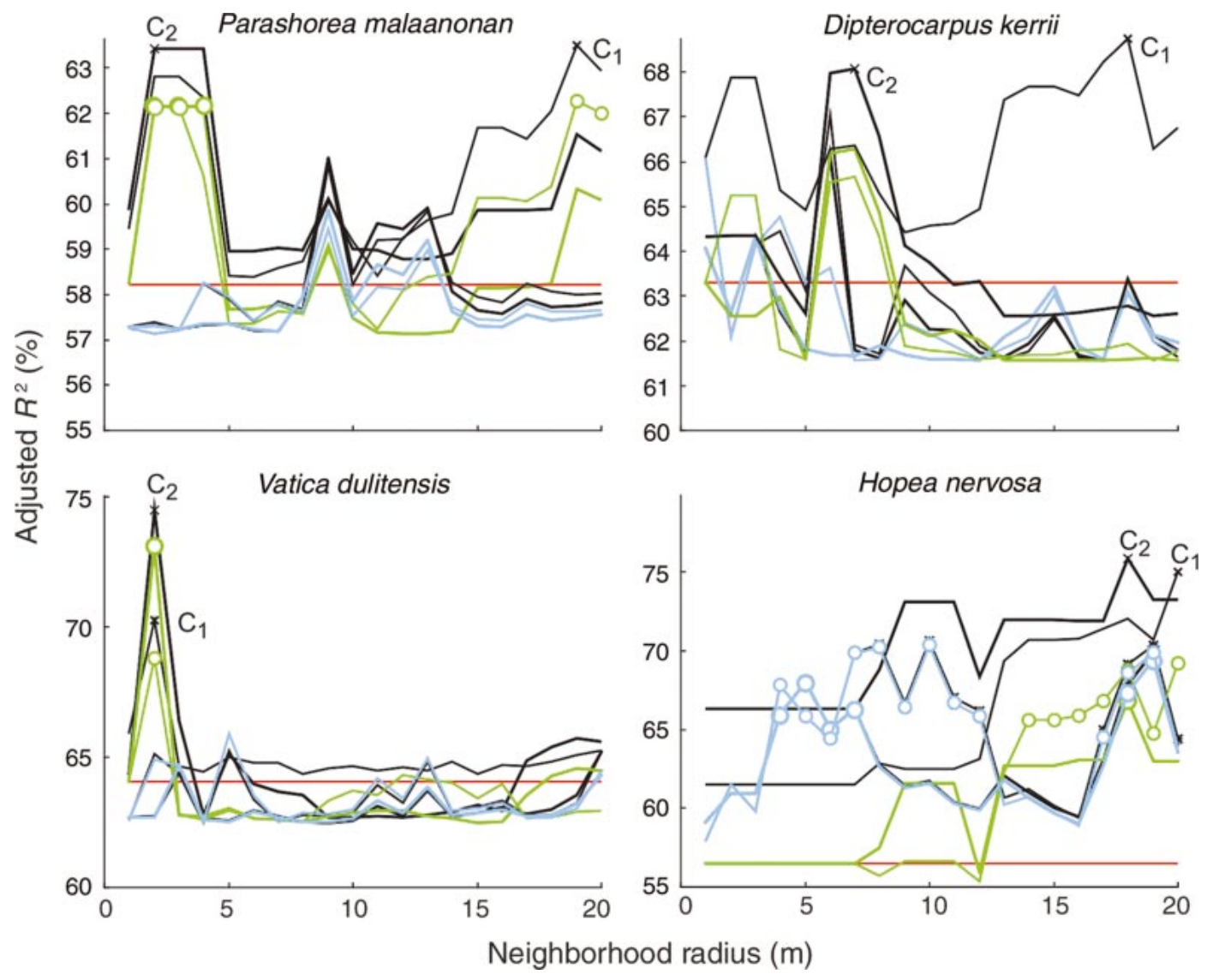

FIG. 1. Continued.

kerrii showed no significance for the models with a single neighborhood term. Nevertheless, model $\mathrm{C}_{1}$ had significant conspecific terms for $P$. malaanonan, with an $R^{2}$ of $64 \%$. In Vatica dulitensis, no model showed significances beyond a neighborhood radius of $2 \mathrm{~m}$. Model $\mathrm{C}_{2}$ reached an $R^{2}$ of $74 \%$ at a heterospecific radius of $20 \mathrm{~m}$ and a conspecific radius of $2 \mathrm{~m}$. Finally, in Hopea nervosa, models $\mathrm{B}_{1}-\mathrm{B}_{4}$ showed significance at small and large neighborhood radii. By contrast, model $\mathrm{B}_{5}$ was significant at neighborhood radii $>14$ $\mathrm{m}$. Model $\mathrm{B}_{6}$ was only significant at $18 \mathrm{~m}$. Both had maximum $R^{2}$ values of $>65 \%$ at 20 and $18 \mathrm{~m}$, respectively. Model $\mathrm{C}_{2}$ reached the highest $R^{2}(76 \%)$ at a heterospecific radius of $7 \mathrm{~m}$ and a conspecific radius of $18 \mathrm{~m}$.

Correlations between the $R^{2}$ values for models $\mathrm{A}$ and $\mathrm{B}_{1}-\mathrm{B}_{6}$ (Table 3 ) across the 10 species were all significant $\left(r_{8}=0.663-0.993, P<0.05\right)$; those between A and $\mathrm{B}_{1}-\mathrm{B}_{4}$ were highly so $(P<0.001)$. $R^{2}$ values for models $\mathrm{A}_{4}$ and $\mathrm{B}_{1}-\mathrm{B}_{4}$ were poorly correlated with those of models $\mathrm{C}_{1}$ and $\mathrm{C}_{2}\left(r_{8}=0.435-0.572, P=0.084-\right.$ 0.209). However, correlations for models $B_{5}, B_{6}, C_{1}$, and $\mathrm{C}_{2}$ were again much higher $\left(r_{8}=0.825-0.974, P\right.$ $<0.003)$.

In summary, in all species except Dipterocarpus ker$r i i$, at least one neighborhood model explained signif- icantly more variation in AGR than did model A. The size term of model A was significant in all species and accounted for $15-64 \%$ of variability in absolute growth rate (Table 3 ). The adjusted $R^{2}$ values for model A were generally higher for dipterocarp species not belonging to the genus Shorea. For six out of 10 species, the neighbor term of model $\mathrm{B}_{1}$ and $\mathrm{B}_{2}$ was significant $(P$ $<0.05)$. For model $\mathrm{B}_{5}$, eight of 10 species had significant neighbor terms; for model $\mathrm{B}_{6}$, all species except Dipterocarpus kerrii and Parashorea malaanonan had significant neighbor terms. Among the models with two neighbor terms, the conspecific term of model $C_{1}$ was significant for nine species and the average adjusted $R^{2}$ across these species was $58 \%$. It increased slightly to $59 \%$, on average, for model $\mathrm{C}_{2}$, which thus performed best among all models in terms of adjusted $R^{2}$.

We used the radius at which model $B_{5}$ reached the first maximum value of adjusted $R^{2}$ to partition the individual trees into groups with and without conspecific neighbors. For each species, the border was decreased from $20 \mathrm{~m}$ to the particular radius that increased the number of available individuals. Average basal area (BA) and absolute growth rate (AGR) of trees in both groups showed considerable differences for AGR (up to more than sixfold), but not for BA (Table 4). Only one of the species (S. pilosa) showed 
TABLE 3. Adjusted $R^{2}$ of size and best-fitting neighborhood regression models over neighborhood distance $(P \leq 0.05)$ for 10 dipterocarp overstory species (ranked in terms of mean basal area in plots 1 and 2 ).

\begin{tabular}{|c|c|c|c|c|c|c|c|c|c|}
\hline \multirow[b]{3}{*}{ Species ( $n$ focal trees) } & \multicolumn{9}{|c|}{ Adjusted $R^{2}(\%)$} \\
\hline & \multirow{2}{*}{$\begin{array}{c}\text { Size } \\
\mathrm{A}\end{array}$} & \multicolumn{6}{|c|}{+ one neighbor term } & \multicolumn{2}{|c|}{$\begin{array}{l}+ \text { two } \\
\text { neighbor } \\
\text { terms }\end{array}$} \\
\hline & & $\mathrm{B}_{1}$ & $\mathrm{~B}_{2}$ & $\mathrm{~B}_{3}$ & $\mathrm{~B}_{4}$ & $\mathrm{~B}_{5}$ & $\mathrm{~B}_{6}$ & $\mathrm{C}_{1}$ & $\mathrm{C}_{2}$ \\
\hline Shorea johorensis (47) & 15 & 43 & 38 & 31 & 29 & 38 & 43 & 57 & 56 \\
\hline Shorea argentifolia (15) & 23 & & & & & 61 & 62 & 79 & 77 \\
\hline Shorea parvifolia (49) & 32 & 37 & 39 & & 37 & 36 & 42 & 41 & 49 \\
\hline Shorea pauciflora (40) & 27 & 40 & 44 & 37 & 41 & & 33 & 44 & 53 \\
\hline Shorea pilosa $(55)$ & 24 & 32 & 28 & & & 38 & 33 & 45 & 35 \\
\hline Shorea fallax (162) & 42 & 44 & 43 & 44 & & 47 & 49 & 49 & 50 \\
\hline Parashorea malaanonan (41) & 58 & & & & & 62 & & 64 & \\
\hline Vatica dulitensis (26) & 64 & & & & & 69 & 73 & 70 & 74 \\
\hline Dipterocarpus kerrii (24) & 63 & & & & & & & & \\
\hline Hopea nervosa (18) & 56 & 71 & 70 & 70 & 69 & 69 & 67 & 75 & 76 \\
\hline
\end{tabular}

Notes: The dependent variable was absolute growth rate (AGR) in basal area (1986-1996), and terms included in the multiple regressions were either size, i.e., basal area (BA) in 1986, or size plus one or size plus two neighbor terms ( $\mathrm{B} B \mathrm{~A}$ of neighbors in 1986). All terms were $\log _{10}$-transformed. Cells with nonsignificant terms $(P>0.05)$ are blank; entries with highly significant terms $(P<0.01)$ are boldface. For the neighborhood models with two terms, this coding corresponds to the conspecific term.

a significant difference in BA. Averaged over the 10 species, mean BA was $49.3 \mathrm{~cm}^{2}$ in the group without conspecific neighbors and $40.5 \mathrm{~cm}^{2}$ in the group with conspecific neighbors. These means were not significantly different $\left(t_{9}=1.47, P=0.176\right)$. In contrast, AGR was significantly higher for four of the six Shorea species in the group without conspecific neighbors than in the group with conspecific neighbors. For another species, Hopea nervosa, this difference was marginally significant. Averaged over the 10 species, AGR was $32.4 \mathrm{~cm}^{2}$ for trees without conspecific neighbors and $14.7 \mathrm{~cm}^{2}$ for trees with conspecific neighbors. This twofold difference in AGR was significant $\left(t_{9}=3.61, P\right.$ $=0.006)$ and remained significant $\left(t_{8}=3.23, P=\right.$ $0.012)$ even if the species in which BA also differed significantly ( $S$. pilosa) was excluded. Moreover, averaged over the six Shorea species, BA was not significantly different, i.e., $51.6 \mathrm{~cm}^{2}$ and $43.0 \mathrm{~cm}^{2}\left(\mathrm{t}_{5}=\right.$ $1.04, P=0.347)$. AGR was $51.2 \mathrm{~cm}^{2}$ for trees without conspecific neighbors and $21.6 \mathrm{~cm}^{2}$ for trees with conspecific neighbors. Again, this difference in AGR was significant $\left(t_{5}=2.58, P=0.049\right)$.

The effect sizes of the neighborhood models with two terms $\left(\mathrm{C}_{1}\right.$ and $\left.\mathrm{C}_{2}\right)$ generally showed stronger effects of conspecific compared to heterospecific neighbors (Table 5a). In Dipterocarpus kerrii, however, heterospecific effects were significantly stronger than conspecific effects. Averaged across the 10 species, the effect size of model $\mathrm{C}_{1}$ for heterospecific neighbors was -0.076 ; for conspecifics, the average effect size was -0.251 . This difference was marginally significant $\left(t_{9}\right.$ $=2.25, P=0.051$, tested with absolute effect sizes). The effects of conspecific larger neighbors were stronger than effects of heterospecific larger neighbors in four out of 10 species. (Table 5b). For the other three species (Shorea parvifolia, S. pauciflora, and S. pilosa) heterospecific larger neighbors had effects very similar effects to those of conspecific larger neighbors. For model $\mathrm{C}_{2}$, the average effect size was -0.095 for heterospecific larger neighbors and -0.296 for conspecific larger neighbors. This difference was marginally significant across all 10 species $\left(t_{9}=2.14, P=0.061\right.$, tested with absolute effect sizes). Across the six species of the genus Shorea, effects of conspecific larger neighbors $(-0.329)$ were significantly stronger $\left(t_{5}=3.06\right.$, $P=0.028$, tested with absolute effect sizes) than effects of heterospecific larger neighbors $(-0.033)$.

\section{Model predictions}

To test predictions from the various models, 20 random samples were drawn per species. Half of the trees in each sample were used to fit the regression model at the neighborhood radius with the highest adjusted $R^{2}$. These estimates were then used to predict the AGR of the other half of the trees, which again were grouped into trees with and without conspecific neighbors (Fig. 2). In Shorea johorensis, S. argentifolia, S. pilosa, and S. fallax, focal trees without conspecific neighbors, on average, had much higher AGRs than did focal trees with conspecific neighbors. Thus the randomizations supported the results presented earlier (cf. Table 4). Moreover, the size model underestimated AGR for focal trees without conspecific neighbors in all four species. In contrast, for trees with conspecific neighbors, the size model predicted higher AGR than that actually measured. If all neighbors were included in a singleneighbor-term model, the predictions did not differ much compared to predictions from the size-alone model. However, single-neighbor-term models taking only conspecific neighbors into account yielded much 
TABLE 4. Basal area (BA in $\mathrm{cm}^{2}$ in 1986) and absolute growth rate in basal area (AGR in $\mathrm{cm}^{2}$, 1986-1996) for focal trees from 10 to $\leq 100 \mathrm{~cm}$ (girth) of 10 overstory species (family Dipterocarpaceae).

\begin{tabular}{|c|c|c|c|c|c|c|c|c|c|c|}
\hline \multirow[b]{3}{*}{ Species } & \multirow[b]{3}{*}{$n$} & \multirow[b]{3}{*}{$r(\mathrm{~m})$} & \multicolumn{6}{|c|}{ Conspecific neighbors within $r$} & \multirow[b]{3}{*}{$P_{\mathrm{BA}}$} & \multirow[b]{3}{*}{$P_{\mathrm{AGR}}$} \\
\hline & & & \multicolumn{3}{|c|}{ Absent } & \multicolumn{3}{|c|}{ Present } & & \\
\hline & & & $n$ & BA & AGR & $n$ & $\mathrm{BA}$ & AGR & & \\
\hline Shorea johorensis & 67 & 6 & 39 & 48.5 & 88.5 & 28 & 46.5 & 29.8 & 0.899 & 0.005 \\
\hline Shorea argentifolia & 18 & 17 & 6 & 35.0 & 209.6 & 12 & 31.6 & 32.2 & 0.755 & 0.012 \\
\hline Shorea parvifolia & 73 & 13 & 20 & 76.5 & 146.8 & 53 & 101.8 & 135.1 & 0.397 & 0.808 \\
\hline Shorea pauciflora & 47 & 7 & 27 & 44.8 & 9.6 & 20 & 41.9 & 11.4 & 0.831 & 0.682 \\
\hline Shorea pilosa & 68 & 5 & 23 & 88.5 & 61.1 & 45 & 32.2 & 11.1 & $<\mathbf{0 . 0 0 1}$ & $<\mathbf{0 . 0 0 1}$ \\
\hline Shorea fallax & 219 & 6 & 72 & 36.9 & 12.7 & 147 & 31.2 & 6.2 & 0.264 & 0.010 \\
\hline Parashorea malaanonan & 76 & 9 & 42 & 62.4 & 16.9 & 34 & 63.1 & 13.1 & 0.973 & 0.558 \\
\hline Vatica dulitensis & 39 & 5 & 18 & 39.8 & 9.7 & 21 & 31.6 & 4.6 & 0.627 & 0.191 \\
\hline Dipterocarpus kerrii & 46 & 7 & 13 & 29.2 & 10.9 & 33 & 36.5 & 7.9 & 0.590 & 0.561 \\
\hline Hopea nervosa & 28 & 14 & 11 & 61.9 & 35.7 & 17 & 26.1 & 9.7 & 0.157 & 0.055 \\
\hline
\end{tabular}

Notes: The individuals ( $n$ giving their number) were divided into groups: one without conspecific neighbors (absent) and one with conspecific neighbors (present). The neighborhood radius $(r)$ was taken where the adjusted $R^{2}$ value of model $\mathrm{B}_{5}$ reached its first maximum. To have sufficient individuals in the group with conspecific neighbors, $r$ was set to a minimum of $5 \mathrm{~m}$. A $t$ test (on $\log _{10}$-transformed values) comparing the means in the two groups was constructed by randomly allocating focal trees to one of the two groups, calculating the $t$ value, and counting the number of $t$ values that were greater than the observed one (on both sides of the distribution). This number, divided by the number of randomizations (1000), is given as $P_{\mathrm{BA}}$ for basal area and $P_{\mathrm{AGR}}$ for absolute growth rate, respectively. Boldface values indicate $P<0.10$.

better predictions than did either of the previous models. Models with two neighbor terms (not shown), yielded predictions very similar to those of the singleneighbor-term models with conspecific neighbors.

\section{Pattern and size analysis}

There was variation in the degree of clumping among the 10 species, but also within species among plots. (Maps of each species' distribution in the plots, and graphs of $\mathrm{L}_{(t)}$ vs. $t$, are found in Appendix B.) Shorea fallax and $S$. pilosa showed the most clumped patterns among the Shorea species. Shorea parvifolia (especially in plot 1) and $S$. pauciflora were the least clumped. S. johorensis was not more clumped than either S. parvifolia or S. pauciflora. For S. argentifolia, there were few individuals per plot, so that pattern analysis must be interpreted with caution. Parashorea malaanonan in plot 1 was almost random, but in plot 2 it was clumped. The remaining three species all showed strikingly clumped spatial patterns. Comparing the five strongly clumped species (S. pilosa, S. fallax, $V$. dulitensis, D. kerrii, and H. nervosa) with those species with no or little evidence of clumping (the other five in Table 3 ), $R^{2}$ values for models $\mathrm{B}_{5}, \mathrm{~B}_{6}, \mathrm{C}_{1}$, and $\mathrm{C}_{2}$ (Table 3 ) were not significantly different $\left(t_{\mathrm{adj} ; 6 \text { or } 7}=\right.$ -1.34 to $-0.11, P=0.221-0.918)$.

Using the numbers of trees of each species in both plots together, the proportions of trees with gbh $<100$ $\mathrm{cm}$ (of those $\geq 10 \mathrm{~cm}$ ) ranged from 0.046 to 0.304 . This ratio was strongly negatively correlated with the $R^{2}$ values in Table 3 for models $\mathrm{A}$ and $\mathrm{B}_{1}-\mathrm{B}_{4}\left(r_{8}=-0.732\right.$ to $-0.760, P=0.011-0.016)$, but for $\mathrm{B}_{5}$ and $\mathrm{B}_{6}$ the correlations were much weaker $\left(r_{8}=-0.318\right.$ and $-0.281, P=0.370$ and 0.432 , respectively), and for $\mathrm{C}_{1}$ and $\mathrm{C}_{2}$ the correlations were near zero $\left(r_{8}=0.026\right.$ and $-0.039, P=0.942$ and 0.914 , respectively). Thus, species with strong conspecific effects were not those with greater proportions of larger, or smaller, trees.

\section{DISCUSSION}

Using individual-based and spatially explicit neighborhood models, we found strong negative effects of neighbors on absolute basal area increment in 10 abundant dipterocarp overstory species of a lowland dipterocarp forest on Borneo. For most of the 10 species, these negative effects were primarily due to conspecific (larger) neighbors. That is, trees with many conspecific neighbors showed markedly reduced basal area increments compared to trees with few or no conspecific neighbors. Averaged over all 10 species, trees without conspecific neighbors grew about twice as fast as those with conspecific neighbors. However, significant negative conspecific effects were only found in four of the six Shorea species. In the other two species ( $S$. pauciflora and $S$. parvifolia), there were no differences in absolute growth rate between trees with or without conspecific neighbors. S. argentifolia was very different in that its conspecific larger neighbors' effect was at distances $\geq 19 \mathrm{~m}$, whereas for $S$. fallax, S. johorensis, and $S$. pilosa, the effect was over the whole range of 5-20 m (Fig. 1). Differences in the strength of the conspecific effect were not explainable by the degree of spatial clumping or by relative size distributions. From the results of our phenomenological neighborhood approach, we can only speculate about the mechanisms that lead to the strong intraspecific negative effects. However, that models with all or heterospecific larger trees as neighbors did not generally perform better than the models with conspecific neighbors suggests that suppression of the focus trees was not due to shading. 
TABLe 5. Effect sizes ( $t^{2} /$ residual $\mathrm{df}+t^{2}$; the sign of $t$ indicates the direction of the effects) for neighbor models with size and two neighbor terms: (a) for model $\mathrm{C}_{1}$, and (b) for model $\mathrm{C}_{2}$.

\begin{tabular}{|c|c|c|c|c|c|c|c|}
\hline \multirow[b]{2}{*}{ Species } & \multicolumn{2}{|c|}{ Radius (m) } & \multicolumn{2}{|c|}{ Effect size } & \multirow[b]{2}{*}{$t$} & \multirow[b]{2}{*}{ df } & \multirow[b]{2}{*}{$P$} \\
\hline & $r_{\mathrm{h}}$ & $r_{\mathrm{c}}$ & het & con & & & \\
\hline \multicolumn{8}{|l|}{ a) Model $\mathrm{C}_{1}$} \\
\hline Shorea johorensis & 11 & 9 & -0.38 & -0.41 & 1.6 & 19 & 0.117 \\
\hline Shorea argentifolia & 18 & 19 & 0.69 & -0.80 & 20.2 & 18 & $<\mathbf{0 . 0 0 1}$ \\
\hline Shorea parvifolia & 12 & 4 & -0.07 & -0.07 & 0.0 & 18 & 0.971 \\
\hline Shorea pauciflora & 10 & 10 & -0.26 & -0.20 & -1.7 & 19 & 0.099 \\
\hline Shorea pilosa & 6 & 5 & -0.14 & -0.26 & 7.0 & 19 & $<0.001$ \\
\hline Shorea fallax & 3 & 4 & -0.03 & -0.11 & 8.1 & 19 & $<\mathbf{0 . 0 0 1}$ \\
\hline Parashorea malaanonan & 9 & 19 & -0.06 & -0.15 & 2.3 & 19 & 0.035 \\
\hline Vatica dulitensis & 5 & 2 & -0.16 & -0.18 & 0.4 & 17 & 0.730 \\
\hline Dipterocarpus kerrii & 1 & 18 & -0.11 & 0.08 & -2.2 & 19 & 0.043 \\
\hline Hopea nervosa & 2 & 20 & -0.23 & -0.41 & 2.2 & 18 & 0.041 \\
\hline \multicolumn{8}{|l|}{ b) Model $\mathrm{C}_{2}$} \\
\hline Shorea johorensis & 15 & 6 & -0.22 & -0.36 & 4.0 & 19 & $<\mathbf{0 . 0 0 1}$ \\
\hline Shorea argentifolia & 18 & 19 & 0.66 & -0.81 & 21.0 & 18 & $<0.001$ \\
\hline Shorea parvifolia & 1 & 14 & -0.17 & -0.21 & 1.3 & 18 & 0.202 \\
\hline Shorea pauciflora & 10 & 10 & -0.34 & -0.35 & 0.1 & 19 & 0.915 \\
\hline Shorea pilosa & 4 & 5 & -0.09 & -0.12 & 0.9 & 19 & 0.383 \\
\hline Shorea fallax & 3 & 6 & -0.03 & -0.12 & 8.6 & 19 & $<0.001$ \\
\hline Parashorea malaanonan & 9 & 19 & -0.06 & -0.11 & 1.2 & 19 & 0.235 \\
\hline Vatica dulitensis & 20 & 2 & -0.18 & -0.47 & 6.4 & 10 & $<\mathbf{0 . 0 0 1}$ \\
\hline Dipterocarpus kerrii & 3 & 7 & -0.12 & -0.05 & -0.7 & 19 & 0.500 \\
\hline Hopea nervosa & 7 & 18 & -0.39 & -0.36 & -0.3 & 18 & 0.758 \\
\hline
\end{tabular}

Notes: The neighborhood radius is designated " $r_{\mathrm{b}}$ " for heterospecific neighbors and " $r_{\mathrm{c}}$ " for conspecific neighbors. Values are averages over 20 randomizations randomly selecting half of the available focal trees (the other half was used to test the predictions of the models). The last three columns give the results of paired $t$ tests comparing the effect size of the two neighbor terms among the 20 randomizations. For some species, df are $<19$ because the regression models could not be fitted: for example, if there were no focal trees with conspecific neighbors. Boldface values indicate significance at $P<0.05$.

The effects that we found for growth can be linked to survival and reproduction and are therefore relevant for population and community dynamics. It is well established that small plants have higher probabilities of dying than large plants, and that small plants produce fewer seeds than large plants. Moreover, plants must reach a threshold size (Weiner 1988, Schmid et al. 1994) in order to start flowering and reproduction, and tropical trees are no exception, as has recently been shown (Uriarte et al. 2005). Hence, any effects on growth and therefore size will have similar effects on survival and reproduction and, ultimately, on population dynamics.

Before we formulate a new hypothesis about possible mechanisms underlying the observed species-specific effects, we will briefly discuss some implications of our results for population and community dynamics of tropical forests. These implications are also relevant for management strategies and simulation models of tropical forests.

Our individual-based neighborhood analysis revealed differences in the spatial extent of conspecific vs. heterospecific effects of neighbors. Spatially explicit competition models have shown that such differences promote coexistence if conspecific interactions occur over larger distances than heterospecific interactions (Murrell and Law 2003). Our analysis un- covered intraspecific negative density-dependent effects at various distances. However, most earlier analyses (reviewed in Wright 2002) only considered effects of conspecifics (not heterospecifics) and plot-based or fixed (rather than flexible) neighborhoods. Taken together, the general conclusion seems to be that intraspecific density-dependent effects on growth are only strong enough to regulate populations of common species (Hubbell et al. 1990, Wright 2002), whereas most species show no species-specific effects. However, our results, together with results from a hurricane-driven tropical forest (Uriarte et al. 2004a, 2005), suggest that intraspecific density dependence may be strong. Therefore, we conclude that not all neighbors are equivalent, as is supposed in the neutral model of Hubbell (2001). In the tropical forest that we studied, conspecific vs. heterospecific interference effects probably play an important role in forest dynamics and community structure.

In tropical forests, decreased performance of individuals around conspecifics has more often been explained by species-specific herbivores and pathogens (Janzen 1970, Connell 1971) rather than resource competition. On the other hand, the many tests of the Janzen-Connell hypothesis have yielded mixed results. For example, Blundell and Peart (1998) found distance- 
Size model
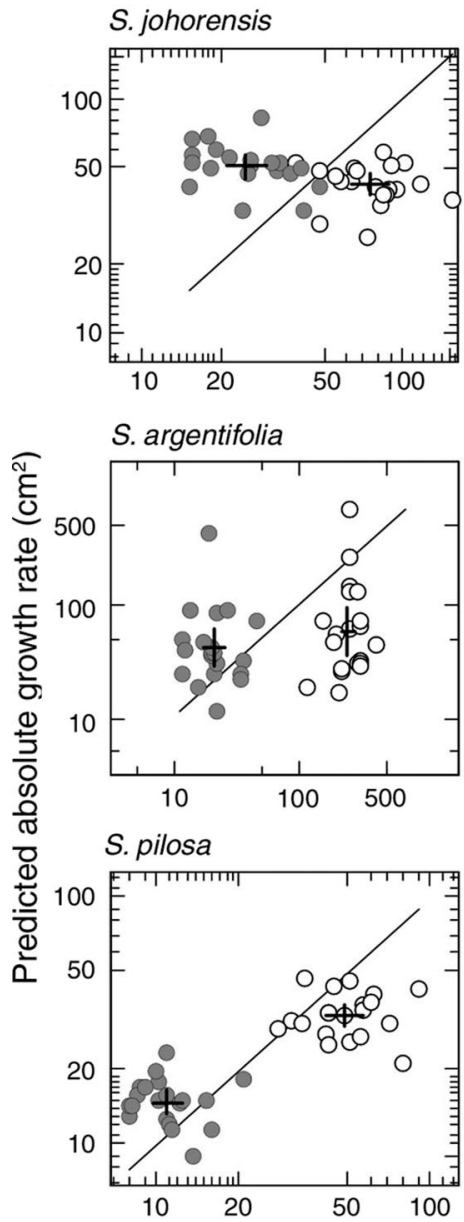

S. fallax

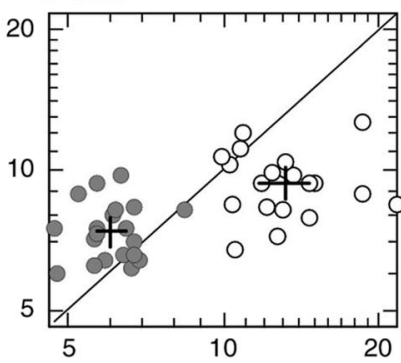

Neighborhood models

With all

neighbors
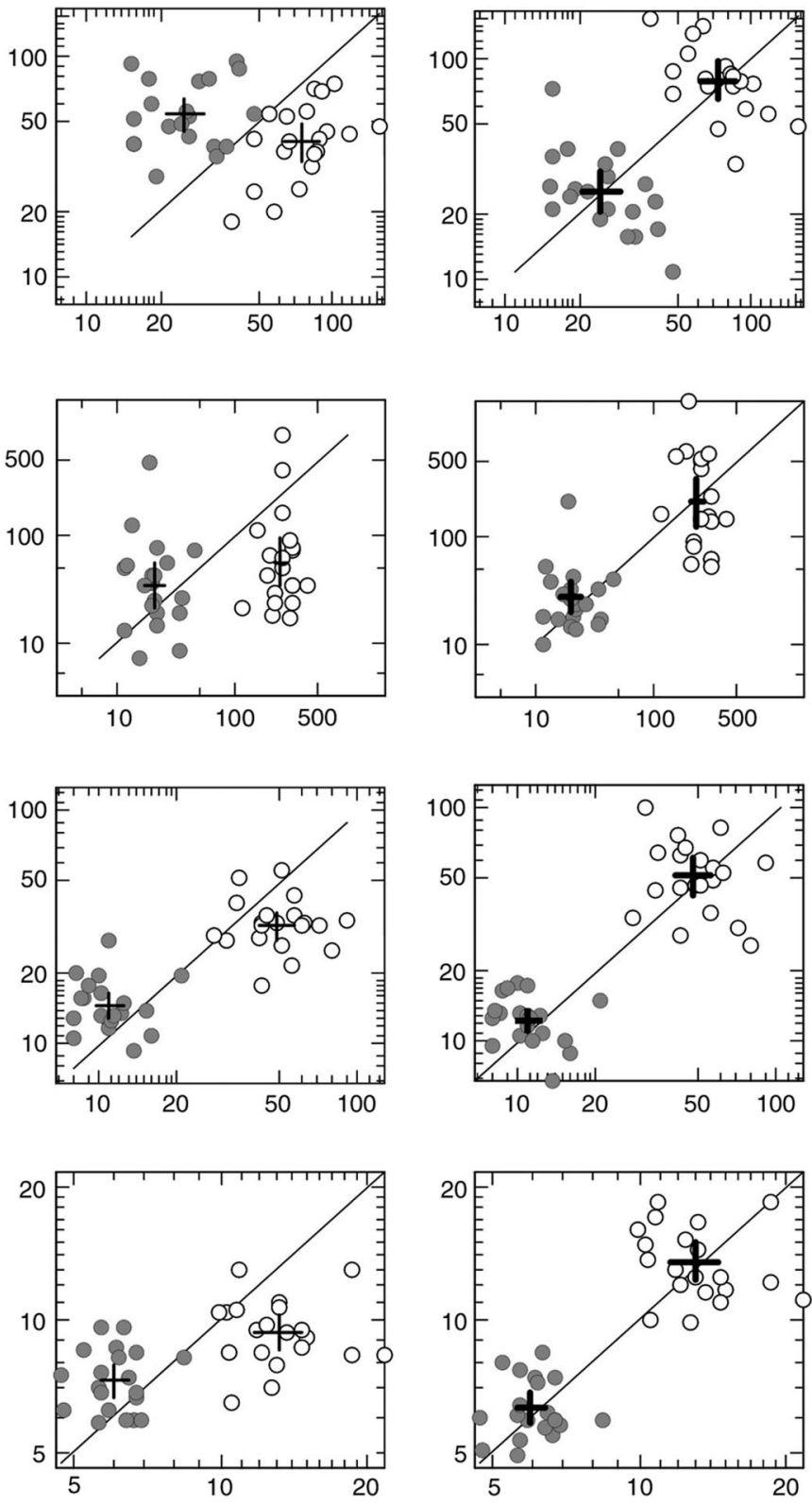

Measured absolute growth rate $\left(\mathrm{cm}^{2}\right)$

FIG. 2. Comparison of measured absolute growth rate (AGR in $\mathrm{cm}^{2}$ ) of basal area from 1986 to 1996 with predicted AGR from multiple regressions including size only, size plus all neighbors $\left(\mathrm{B}_{1}\right)$, and size plus conspecific neighbors $\left(\mathrm{B}_{5}\right)$. Random samples $(n=20)$ were drawn for each of four Shorea species (S. johorensis, S. argentifolia, S. pilosa, and S. fallax). Half of the trees of each sample were used to fit the regression model and the other half were grouped into trees with (solid circles) and without (open circles) conspecific neighbors. Large crosses indicate the means ( \pm 2 SE) over 20 samples in each group. Predicted group means within \pm 2 SE of the measured AGR are highlighted with thick crosses. 
dependent effects of herbivores for two out of four Shorea species and cautioned against generalizations regarding distance-dependent effects in diverse forests. Indeed, a recent meta-analysis found no general support for the distance-dependent predictions of the JanzenConnell hypothesis and concluded that further testing to explore this hypothesis as a diversity-maintaining mechanism is unnecessary (Hyatt et al. 2003). Moreover, local species-specific density dependence, mediated through specialist enemies of offspring such as fungal pathogens and insect seed predators, only facilitates coexistence in spatially explicit simulations when both offspring and enemies disperse over short distances (Adler and Muller-Landau 2005).

We hypothesize that the varying conspecific neighborhood effect might be a function of the degree of host specificity of the ectomycorrhizae. Those species with very strong conspecific effects are postulated to have highly specific fungal symbionts. The ectomycorrhizal status of the Dipterocarpaceae is well established (Malloch et al. 1980, Alexander and Högberg 1986, Ducousso et al. 2004), but the degree of host specificity appears to be variable. Studies to date on Shorea species show that they may have roughly $10-$ 30 fungal types (or species) on their roots, but one or two species frequently dominate (Becker 1983, Smits 1983, Lee and Alexander 1996, Ingelby et al. 1998). Nevertheless, some species of fungi are specialists and others are broad generalists (Janos 1983, Alexander 1989). Across sites, the same tree species may have a different composition of ectomycorrhizae (Lee and Alexander 1996). Finally, ectomycorrhizal associations of dipterocarps have been shown to influence the accessibility of organic nutrients from leaf litter (Brearley et al. 2003).

Our results show that small trees $(10$ to $<100 \mathrm{~cm}$ gbh) are suppressed in their growth when they have adults of the same species as neighbors. Because most of the large dipterocarps are still growing fast (the forest has not yet reached its expected maximum basal area for the site; Newbery et al. 1992), we propose that they drain resources from the smaller trees via mycelial networks. Although carbon is probably at a premium for small trees in the understory, and they gain it partly from the larger trees, large trees may take phosphorus from the smaller ones and thus slow their growth. To acquire phosphorus, mycorrhizae allow the large trees to expand their root systems by connecting with and using the smaller trees. We predict that $S$. johorensis, S. argentifolia, S. pilosa, S. fallax, V. dulitensis, and $H$. nervosa might have highly specific ectomycorrhizae, whereas S. parvifolia, S. pauciflora, P. melaanon$a n$, and $D$. kerrii have less species-specific or no ectomycorrhizae. This is a completely new way of looking at conspecific neighbor interactions between trees.

\section{ACKNOWLEDGMENTS}

We thank E. J. F. Campbell, D. N. Kennedy, L. Madani, G. H. Petol, C. E. Ridsdale, and M. J. Still for field and taxonomic assistance in completing the 1986 and 1996 plot enumerations. Permission to conduct research in Malaysia was kindly granted by the Economic Planning Unit of the Prime Minister's Office, Kuala Lumpur, and to work at Danum by the Danum Valley Management Committee. We are grateful to R. C. Ong, Sabah Forest Department, for local coordination, and to G. Reynolds, Royal Society South-East Asia Rain Forest Research Programme, for site support at Danum. This paper is publication A/413 of the Programme.

\section{Literature Cited}

Adler, F. R., and H. C. Muller-Landau. 2005. When do localized natural enemies increase species richness? Ecology Letters 8:438-447.

Alexander, I. J. 1989. Mycorrhizas in tropical forests. Pages 169-188 in J. Proctor, editor. Mineral nutrient in tropical and savanna ecosystems. Blackwell Scientific Publications, Oxford, UK.

Alexander, I. J., and P. Högberg. 1986. Ectomycorrhizas of tropical angiospermous trees. New Phytologist 102:541549.

Ashton, P. S. 1982. Dipterocarpaceae. Flora Malesiana 9: 237-552. Martinus Nijhoff Publishers, The Hague, The Netherlands.

Ashton, P. S. 1988. Dipterocarp biology as a window to the understanding of tropical forest structure. Annual Review of Ecology and Systematics 19:347-370.

Becker, P. 1983. Ectomycorrhizae on Shorea (Dipterocarpaceae) seedlings in a lowland Malaysian rainforest. Malaysian Forester 46:146-170.

Blundell, A. G., and D. R. Peart. 1998. Distance-dependence in herbivory and foliar condition for juvenile Shorea trees in Bornean dipterocarp rain forest. Oecologia 117:151-160.

Brearley, F. Q., M. C. Press, and J. D. Scholes. 2003. Nutrients obtained from leaf litter can improve the growth of dipterocarp seedlings. New Phytologist 160:101-110.

Brown, N., M. Press, and D. Bebber. 1999. Growth and survivorship of dipterocarp seedlings: differences in shade persistence create a special case of dispersal limitation. Philosophical Transactions of the Royal Society of London B 354:1847-1855.

Cohen, J. 1977. Statistical power analysis for the behavioral sciences. Academic Press, London, UK.

Condit, R., et al. 2000. Spatial patterns in the distribution of tropical tree species. Science 288:1414-1418.

Condit, R., S. P. Hubbell, and R. B. Foster. 1992. Recruitment near conspecific adults and the maintenance of tree and shrub diversity in a neotropical forest. American Naturalist 140:261-286.

Connell, J. H. 1971. On the role of natural enemies in preventing competitive exclusion in some marine animals and in rain forest trees. Pages 298-313 in J. P. den Boer and G. R. Gradwell, editors. Dynamics of populations. Centre for Agricultural Publishing and Documentation, Wageningen, The Netherlands.

Connell, J. H., J. G. Tracey, and L. J. Webb. 1984. Compensatory recruitment, growth, and mortality as factors maintaining rain forest tree diversity. Ecological Monographs 54:141-164.

Dieckmann, U., R. Law, and J. A. J. Metz, editors. 2000. The geometry of ecological interactions: simplifying spatial complexity. Cambridge University Press, Cambridge, UK

Ducousso, M., G. Bena, C. Bourgeois, B. Buyck, G. Eyssartier, M. Vincelette, R. Rabevohitra, L. Randrihasipara, B. Dreyfus, and Y. Prin. 2004. The last common ancestor of Sarcolaenaceae and Asian dipterocarp trees was ectomycorrhizal before the India-Madagascar separation, about 88 million years ago. Molecular Ecology 13:231-236. 
Duncan, R. P. 1995. A correction for including competitive asymmetry in measures of local interference in plant populations. Oecologia 103:393-396.

Gourlet-Fleury, S. 1998. Competition indices in a tropical moist forest: trials on the sylvicultural experimental plots of Paracou (French Guiana). Annals of Forest Science 55: 623-653.

Gourlet-Fleury, S., and F. Houllier. 2000. Modelling diameter increment in a lowland evergreen rain forest in French Guiana. Forest Ecology and Management 131:269-289.

Haase, P. 1995. Spatial pattern analysis in ecology based on Ripley's K-function: introduction and methods of edge correction. Journal of Vegetation Science 6:575-582.

Harms, K. E., R. Condit, S. P. Hubbell, and R. B. Foster. 2001. Habitat associations of trees and shrubs in a 50-ha neotropical forest plot. Journal of Ecology 89:947-959.

Harms, K. E., S. J. Wright, O. Calderon, A. Hernandez, and E. A. Herre. 2000. Pervasive density-dependent recruitment enhances seedling diversity in a tropical forest. Nature 404:493-495.

Harper, J. L. 1977. The population biology of plants. Academic Press, London, UK.

Hilborn, R., and M. Mangel. 1997. The ecological detective: confronting models with data. Princeton University Press, Princeton, New Jersey, USA.

Hubbell, S. P. 2001. The unified neutral theory of biodiversity and biogeography. Princeton University Press, Princeton, New Jersey, USA.

Hubbell, S. P., J. A. Ahumada, R. Condit, and R. B. Foster 2001. Local neighborhood effects on long-term survival of individual trees in a neotropical forest. Ecological Research 16:859-875.

Hubbell, S. P., R. Condit, and R. B. Foster. 1990. Presence and absence of density dependence in a neotropical tree community. Philosophical Transactions of the Royal Society of London B 330:269-281.

Huston, M. A. 1994. Biological diversity: the coexistence of species on changing landscapes. Cambridge University Press, Cambridge, UK.

Huston, M., D. DeAngelis, and W. Post. 1988. New computer models unify ecological theory. BioScience 38:682-691.

Hyatt, L. A., M. S. Rosenberg, T. G. Howard, G. Bole, W. Fang, J. Anastasia, K. Brown, R. Grella, K. Hinman, J. P. Kurdziel, and J. Gurevitch. 2003. The distance dependence prediction of the Janzen-Connell hypothesis: a meta-analysis. Oikos 103:590-602.

Ingelby, K., R. C. Munro, M. Noor, P. A. Mason, and M. J. Clearwater. 1998. Ectomycorrhizal populations and growth of Shorea parvifolia (Dipterocarpaceae) seedlings regenerating under different forest canopies following logging. Forest Ecology and Management 111:171-179.

Janos, D. P. 1983. Tropical mycorrhizal fungi, nutrient cycles and plant growth. Pages 327-345 in S. L. Sutton, T. C. Whitmore, and A. C. Chadwick, editors. Tropical rain forest: ecology and management. Blackwell Scientific Publications, Oxford, UK.

Janzen, D. H. 1970. Herbivores and the number of tree species in tropical forests. American Naturalist 104:501-528.

Keane, R. E., M. Austin, C. Field, A. Huth, M. J. Lexer, D. Peters, A. Solomon, and P. Wyckoff. 2001. Tree mortality in gap models: application to climate change. Climatic Change 51:509-540.

Köhler, P., T. Ditzer, and A. Huth. 2000. Concepts for the aggregation of tropical tree species into functional types and the application to Sabah's lowland rain forests. Journal of Tropical Ecology 16:591-602.

Lee, S. S., and I. J. Alexander. 1996. The dynamics of ectomycorrhizal infection of Shorea leprosula seedlings in Malaysian rain forests. New Phytologist 132:297-305.
Liu, J. G., and P. S. Ashton. 1995. Individual-based simulation models for forest succession and management. Forest Ecology and Management 73:157-175.

Liu, J. G., and P. S. Ashton. 1998. FORMOSAIC: an individual-based spatially explicit model for simulating forest dynamics in landscape mosaics. Ecological Modelling 106: 177-200.

Malloch, D. W., K. A. Pirozynski, and P. H. Raven. 1980 Ecological and evolutionary significance of mycorrhizal symbiosis in vascular plants (a review). Proceedings of the National Academy of Sciences (USA) 77:2113-2118.

Meijer, W., and G. H. S. Wood. 1964. Dipterocarps of Sabah. Sabah Forest Record Number 5. Sabah Forest Department, Sandakan, Malaysia.

Moravie, M.-A., M. Durand, and F. Houllier. 1999. Ecological meaning and predictive ability of social status, vigour and competition indices in a tropical rain forest (India). Forest Ecology and Management 117:221-240.

Murrell, D. J., and R. Law. 2003. Heteromyopia and the spatial coexistence of similar competitors. Ecology Letters 6:48-59.

Newbery, D. M., E. J. F. Campbell, Y. F. Lee, C. E. Ridsdale, and M. J. Still. 1992. Primary lowland dipterocarp forest at Danum Valley, Sabah, Malaysia: structure, relative abundance and family composition. Philosophical Transactions of the Royal Society of London B 335:341-356.

Newbery, D. M., E. J. F. Campbell, J. Proctor, and M. J. Still. 1996. Primary lowland dipterocarp forest at Danum Valley, Sabah, Malaysia. Species composition and patterns in the understorey. Vegetatio 122:193-220.

Newbery, D. M., D. N. Kennedy, G. H. Petol, L. Madani, and C. E. Ridsdale. 1999. Primary forest dynamics in lowland dipterocarp forest at Danum Valley, Sabah, Malaysia, and the role of the understorey. Philosophical Transactions of the Royal Society of London B 354:1763-1782.

Newbery, D. M., and J. Proctor. 1984. Ecological studies in four contrasting lowland rain forests in Gunung Mulu national Park, Sarawak. IV. Associations between tree distribution and soil factors. Journal of Ecology 72:475-493.

Newbery, D. M., E. Renschaw, and E. F. Brünig. 1986. Spatial pattern of trees in Kerangas forest, Sarawak. Vegetatio 65:77-89.

Newman, M. F., P. F. Burgess, and T. C. Whitmore. 1996. Borneo Islands light hardwoods. Manuals of dipterocarps for foresters. Royal Botanic Garden, Edinburgh, UK; and Centre for International Forestry Research, Jakarta, Indonesia.

Newman, M. F., P. F. Burgess, and T. C. Whitmore. 1998. Borneo Islands medium and heavy hardwoods. Manuals of dipterocarps for foresters. Royal Botanic Garden, Edinburgh, UK; and Centre for International Forestry Research, Jakarta, Indonesia.

Okuda, T., N. Kachi, S. K. Yap, and N. Manokaran. 1997. Tree distribution pattern and the fate of juveniles in a lowland tropical rain forest-implications for regeneration and maintenance of species diversity. Plant Ecology 131:155-171.

Pacala, S. W. 1997. Dynamics of plant communities. Pages 532-555 in M. J. Crawley, editor. Plant ecology. Blackwell Scientific Publications, Oxford, UK.

Pacala, S. W., C. D. Canham, J. Saponara, J. A. Silander, R. K. Kobe, and E. Ribbens. 1996. Forest models defined by field measurements: estimation, error analysis, and dynamics. Ecological Monographs 66:1-43.

Pacala, S. W., C. D. Canham, and J. A. Silander. 1993. Forest models defined by field measurements: I. The design of a northeastern forest simulator. Canadian Journal of Forest Research 23:1980-1988.

Palmiotto, P. A., S. J. Davies, K. A. Vogt, M. S. Ashton, D. J. Vogt, and P. S. Ashton. 2004. Soil-related habitat spe- 
cialization in dipterocarp rain forest tree species in Borneo. Journal of Ecology 92:609-623.

Peters, H. A. 2003. Neighbour-regulated mortality: the influence of positive and negative density dependence on tree populations in species-rich tropical forests. Ecology Letters 6:757-765.

Phillips, P. D., T. E. Brash, I. Yasman, P. Subagyo, and P. R. van Gardingen. 2003. An individual-based spatially explicit tree growth model for forests in East Kalimantan (Indonesian Borneo). Ecological Modelling 159:1-26.

Phillips, P. D., I. Yasman, T. E. Brash, and P. R. van Gardingen. 2002. Grouping tree species for analysis of forest data in Kalimantan (Indonesian Borneo). Forest Ecology and Management 157:205-216.

Plotkin, J. B., M. D. Potts, N. Leslie, N. Manokaran, J. LaFrankie, and P. S. Ashton. 2000. Species-area curves, spatial aggregation, and habitat specialization in tropical forests. Journal of Theoretical Biology 207:81-99.

Potts, D. M., P. S. Ashton, L. S. Kaufman, and J. B. Plotkin. 2002. Habitat patterns in tropical rain forests: a comparison of 105 plots in Northwest Borneo. Ecology 83:2782-2797.

Richards, P. W. 1996. The tropical rain forest. Second edition. Cambridge University Press, Cambridge, UK.

Ripley, B. D. 1977. Modelling spatial patterns. Journal of the Royal Statistical Society, B 39:172-212.

Sakamoto, Y., M. Ishiguro, and G. Kitagawa. 1986. Akaike information criterion statistics. KTK (Tokyo) Scientific Publishers, Riedel, Dordrecht, The Netherlands.

Schmid, B., W. Polasek, J. Weiner, A. Krause, and P. Stoll. 1994. Modeling of discontinuous relationships in biology with censored regression. American Naturalist 143:494507.

Schwinning, S., and J. Weiner. 1998. Mechanisms determining the degree of size asymmetry in competition among plants. Oecologia 113:447-455.

Smits, W. T. M. 1983. Dipterocarps and mycorrhiza: an ecological adaptation and a factor in forest regeneration. Flora Malesiana Bulletin 36:3926-3937.

Stoll, P., and J. Weiner. 2000. A neighborhood view of interactions among individual plants. Pages 11-27 in U. Dieckmann, R. Law, and J. A. J. Metz, editors. The geometry of ecological interactions: simplifying spatial complexity. Cambridge University Press, Cambridge, UK.
Stoll, P., J. Weiner, and B. Schmid. 1994. Growth variation in a naturally established population of Pinus sylvestris. Ecology 75:660-670.

Thomas, S. C., and J. Weiner. 1989. Including competitive asymmetry in measures of local interference in plant populations. Oecologia 80:349-355.

Uriarte, M., C. D. Canham, J. Thompson, J. K. Zimmerman, and N. Brokaw. 2005. Seedling recruitment in a hurricanedriven tropical forest: light limitation, density-dependence and the spatial distribution of parent trees. Journal of Ecology 93:291-304.

Uriarte, M., C. D. Canham, J. Thompson, and J. K. Zimmerman. 2004a. A neighborhood analysis of tree growth and survival in a hurricane-driven tropical forest. Ecological Monographs 74:591-614.

Uriarte, M., R. Condit, C. D. Canham, and S. P. Hubbell. $2004 b$. A spatially explicit model of sapling growth in a tropical forest: does the identity of neighbours matter? Journal of Ecology 92:348-360.

Walsh, R. P. D., and D. M. Newbery. 1999. The ecoclimatology of Danum, Sabah, in the context of the world's rainforest regions, with particular reference to dry periods and their impact. Philosophical Transactions of the Royal Society of London B 354:1869-1883.

Webb, C. O., and D. R. Peart. 2000. Habitat association of trees and seedlings in a Bornean rain forest. Journal of Ecology 88:464-478.

Weiner, J. 1988. The influence of competition on plant reproduction. Pages 228-245 in J. Lovett Doust and L. Lovett Doust, editors. Plant reproductive ecology: patterns and strategies. Oxford University Press, New York, New York, USA.

Whitmore, T. C. 1984. Tropical rain forests of the Far East. Second edition. Clarendon Press, Oxford, UK.

Wills, C., and R. Condit. 1999. Similar non-random processes maintain diversity in two tropical rainforests. Proceedings of the Royal Society of London B 266:1445-1452.

Wills, C., R. Condit, R. B. Foster, and S. P. Hubbell. 1997. Strong density- and diversity related effects help to maintain tree species diversity in a neotropical forest. Proceedings of the National Academy of Sciences (USA) 94:12521257.

Wright, S. J. 2002. Plant diversity in tropical forests: a review of mechanisms of species coexistence. Oecologia 130:114.

\section{APPENDIX A}

Supplementary tables with adjusted $R^{2}$ values, best-fitting radii, estimates, standard errors, and $t$ and $P$ values of the regression coefficients are available in ESA's Electronic Data Archive: Ecological Archives E086-166-A1.

\section{APPENDIX B}

Spatial patterns and combined count-distance $\left(L_{(t)}\right.$ vs. distance $t$ in meters) of dipterocarp species in the two 4-ha plots at Danum are available in ESA's Electronic Data Archive: Ecological Archives E086-166-A2. 